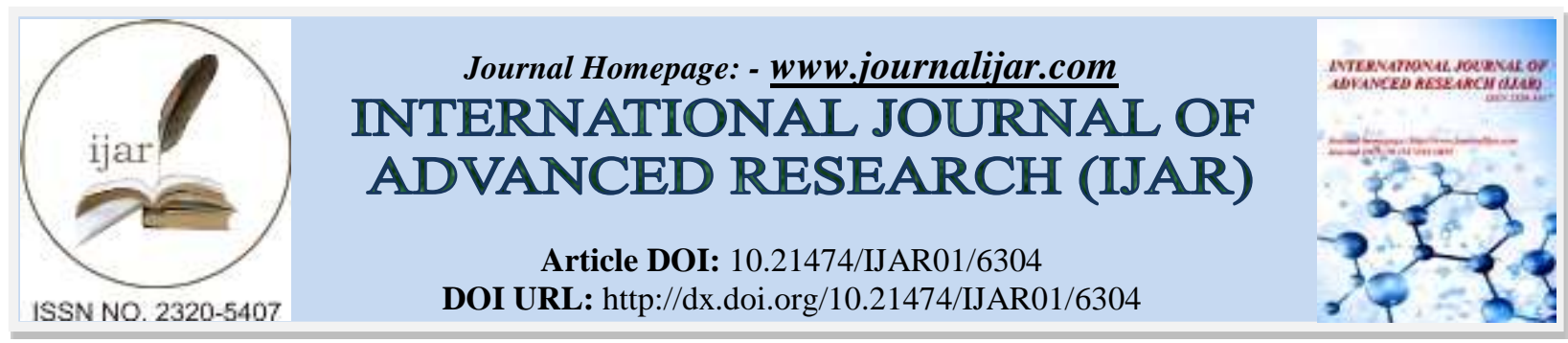

RESEARCH ARTICLE

\title{
RELATIONSHIP BETWEEN QUALITY OF LIFE AND PHYSICAL PERFORMANCE IN MODERATE OA KNEE PATIENTS IN TERTIARY HEALTH CARE CENTRE.
}

\author{
Harshita S.Somkuwar ${ }^{1}$, Chetana A.Kunde ${ }^{2}$ and Suvarna S.Ganvir ${ }^{3}$. \\ 1. Department of physiotherapy, DVVPF's college of physiotherapy Ahmednagar, India. \\ 2. MPT, Department of Neurosciences, DVVPF's college of physiotherapy Ahmednagar, India. \\ 3. MPTh, Department of Neurosciences, DVVPF's college of physiotherapy Ahmednagar, India.
}

\section{Manuscript Info}

\section{Manuscript History}

Received: 14 November 2017

Final Accepted: 16 December 2017

Published: January 2018

Key words:-

Knee osteoarthritis, quality of life, physical performance, moderate OA knee

\begin{abstract}
Background: In moderate OA (osteoarthritis) knee there is obvious damage to cartilage and the space between the bones begins to narrow. Patients with moderate OA knee are likely to experience frequent knee pain when walking, running, bending, and kneeling, etc. Also they experience joint stiffness after sitting for long duration or after waking up in the morning. Thus we intend to find out which factors of quality of life affects physical performance in these patients.

Methodology: An observational study was conducted in DVVPF'S Vikhe Patil Memorial Hospital and D.V.V.P.F'S OPD of COPT on 22 patients with moderate OA knee patients. These patients were selected according to Kellgren and Lawrence grading criteria. Their quality of life was assessed with the help of WOMAC scale, whereas physical performance was assessed with the help of Time Up and Go (TUG).

Result: According to our study which was done on 22 patients with mean age for male being 62.5 and for female being 60.93 , we found out that there is a moderately positive correlation of pain (' $r$ ' value- $0.64, \mathrm{P}$ value-0.0011), stiffness (' $r$ ' value-0.59,P value-0.0033) and physical function (' $r$ ' value-0.67, P value-0.0006) with physical performance. The total WOMAC score and TUG had a strongly positive correlation (' $r$ ' value-0.8239, $\mathrm{P}$ value-<0.0001). Thus indicating that patients with moderate OA knee not only had a poor quality of life but also had reduced physical function

Conclusion: There is strong positive correlation between quality of life and physical performance. With increase in pain, stiffness and physical function there is increased difficulty in performing physical performance. Thus moderate OA knee affects both quality of life and physical performance.

Copy Right, IJAR, 2018,. All rights reserved.
\end{abstract}

\section{Introduction:-}

Knee osteoarthritis (OA) is a painful, chronic degenerative joint disorder affecting a large portion of the older population worldwide. ${ }^{1}$ Though OA can occur in all joints due to ageing, it is more commonly seen in weight bearing joints like knee, hip, ankle and spine. Among all the joints in the body, osteoarthritis affects the knee joint most. ${ }^{2,3}$ The prevalence of knee OA is higher in women compared to men and this gender difference seems more 
exaggerated among Asian women. ${ }^{4}$ The 2 most common symptoms are pain and loss of physical function, both of which are disabling and limiting patients' ability to work and carry out their normal daily activities. ${ }^{5-7}$ Severe pain, a hallmark symptom of knee $\mathrm{OA}$, is also a major predisposing factor for increased fall risk. ${ }^{8-10}$

A fall is defined as unintentionally coming to rest on the ground, or at some other lower level, not as a result of a major intrinsic event such as a faint or stroke, seizure, or an overwhelming external hazard like hit by a vehicle. ${ }^{11}$ Falls in the elderly have become a serious problem and are major contributors to functional decline and health care utilization. Women with wide spread musculoskeletal pain have $66 \%$ increased fall risk than those with no pain or mild pain. ${ }^{12}$ Fear of fall and balance impairment in people with osteoarthritis of knee joint is a major cause of loss of independence which effect on the physical function in them. According to Harrison AL et al functional self-efficacy is an important factor affecting the functional performance outcome with OA of the knee ${ }^{13}$.

Difficulty in walking, stair climbing, and squatting are common patient complaints that greatly interfere with activities of daily living and recreation. Consequently, most research on knee OA has attempted to quantify the magnitude of physical disability associated with this disease and the impact of various treatments on outcomes such as pain severity and physical functioning. However, the physical manifestations of knee OA have direct impact on other aspects of patient's lives such as social interactions, and sleep quality. Therefore, health-related quality of life (HRQoL) measures are relevant and important adjunct outcomes that help quantify the physical and social impact of knee OA and of various OA therapies. ${ }^{14}$

Ahmednagar, being a rural set up, it is usually seen that individuals from age group 50-65 years have knee pain and OA. Since, the major occupation here being farming, they have increased forward bending, squatting activities etc. which aggravates their knee pain.

Hence we aim to study relationship between health related QOL (WOMAC) and physical performance in moderate OA knee patients so that we can find out how quality of life is affected in elderly individuals and does the components like pain, stiffness, and physical function affects the physical performance in them and to find out physical performance and quality of life in unilateral and bilateral OA knee patients, so that we can modify our treatment accordingly.

\section{Methodology:-}

This is an observational study which was conducted at D.V.V.P.F'S Vikhe Patil Memorial hospital for a period of one year. 22 subjects were selected for this study by means of simple random sampling. Patients with grade III OA knee were included. The age group selected for this study was 50-65 year of both the genders. Patients with cognitive impairment, Parkinson's disease and other neurological disorders were excluded. Also patients with RA and OA of grade less than III according to Kellgren Lawrence were excluded.

\section{Procedure:-}

After the approval of Institutional Ethical Committee, of D.V.V.P.F's College of physiotherapy, the subjects were selected based on the inclusion and exclusion criteria and were explained about the study and an informed consent was obtained from all subjects. The demographic data and history of falls was obtained. They were then sent for radiological examination and then were categorized as grade III OA knee according to Kellgren and Lawrence grading criteria. The subjects were then explained the procedure of the test. The subjects were then asked to perform TUG test. The subjects performed the test for 3 times and the mean of the 3 was recorded. Then WOMAC questionnaire was administered for accessing QOL.

\section{Outcome Measures:-}

Womac:-

Western Ontario and McMaster Universities Arthritis Index (WOMAC) is a 24-item questionnaire with 3 subscales measuring: pain (5 items), stiffness ( 2 items) and physical function (17 items). A lower score indicates a better outcome. 


\section{Physical Performance Test:- \\ Turn up and go test:-}

Turn up and go (TUG) test measures the time it takes for a patient to rise from an armed chair, walk $3 \mathrm{~m}$, turn and return to sitting in the same chair. Subjects were instructed to walk as quickly as they feel safe and comfortable. The use of the arms of the chair was permitted to stand up and sit down. The TUG test is a simple test used to assess a person's mobility and requires both static and dynamic stability.

\section{Statistical Tests:-}

Correlation coefficient was done to analyse the relationship between QOL and physical performance. To compare physical performance in patients with unilateral and bilateral OA knee Mann-Whitney test was used as data was not equally distributed.to compare quality of life in patients with unilateral and bilateral OA knee unpaired test was used as data passed normality test. Normality was checked by Kolmogorov and Smirnov test.

\section{Result:-}

Table 1:- Mean age of male and female patients

\begin{tabular}{|l|l|}
\hline Sex & Mean Age \\
\hline Male & 62.5 \\
\hline Female & 60.93 \\
\hline
\end{tabular}

Table 2:- Gender wise distribution of patients with unilateral and bilateral moderate OA knee.

\begin{tabular}{|l|l|l|l|}
\hline Subjects & Unilateral OA & Bilateral OA & Total \\
\hline Male & 2 & 4 & 6 \\
\hline Female & 11 & 5 & 16 \\
\hline Total & 13 & 9 & 22 \\
\hline
\end{tabular}

Table 3:- Correlation between Womac components and TUG in moderate OA knee patients.

\begin{tabular}{|l|l|l|}
\hline Womac v/s TUG & Correlation 'r' value & P value \\
\hline Pain v/s TUG & 0.64 & 0.0011 \\
\hline Stiffness v/s TUG & 0.59 & 0.0033 \\
\hline Physical function v/s TUG & 0.67 & 0.0006 \\
\hline
\end{tabular}

Table 4:- Correlation between quality of life and physical performance in moderate OA knee patients.

\begin{tabular}{|l|l|l|l|}
\hline Scales & Number of subjects & Correlation 'r' & P value \\
\hline Womac & 22 & 0.82 & $<0.0001$ \\
\hline Time up and go & & & \\
\hline
\end{tabular}

Table 5:- Difference in physical performance and quality of life in patients with unilateral and bilateral OA knee

\begin{tabular}{|c|c|c|c|c|c|c|}
\hline 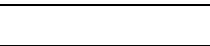 & \multicolumn{3}{|l|}{ TUG } & \multicolumn{3}{|c|}{ WOMAC } \\
\hline & Mean & $\begin{array}{l} \pm \text { Std } \\
\text { deviation }\end{array}$ & $P$ value & Mean & $\begin{array}{l} \pm \text { Std } \\
\text { deviation }\end{array}$ & $P$ value \\
\hline $\begin{array}{l}\text { Unilateral } \\
\text { OA }\end{array}$ & 22.45 & 4.11 & 0.0001 & 71.69 & 8.19 & 0.0237 \\
\hline Bilateral OA & 29.59 & 3.98 & & 79.44 & 5.7 & \\
\hline
\end{tabular}

In our study we took mean age of patients with moderate OA knee which was 62.5 for males and 60.93 for females (Table 1). Out of the total 22 assessed patients there were total 13 patients with unilateral OA knee and 9 patients with bilateral OA knee (Table 2). After analysing data showed moderately positive correlation between Womac components with TUG in moderate OA knee, i.e. pain (' $r$ ' value- 0.64 , P value- 0.0011 ), stiffness (' $r$ ' value- 0.59 , $P$ value-0.0033), physical performance (' $r$ ' value $-0.67, \mathrm{P}$ value-0.0006) with TUG (Table 3 ). Also there is strong positive correlation of WOMAC and TUG ('r' value-0.82, P value- <0.0001) (Table 4), which indicates as the Quality of life decreases, performance time on TUG also decreases. Physical performances i.e. TUG in patients with bilateral OA knee was more compared to in patients with unilateral OA knee. Also in quality of life, in bilateral OA knee patients was more compared to unilateral patients. Hence significant difference was found out for TUG between unilateral OA knee $(22.45 \pm 4.11)$ and bilateral OA knee (29.59 \pm 3.98$)$; and for physical performance between unilateral OA knee (71.69 \pm 8.19$)$ and bilateral OA knee (79.44 \pm 5.7$)$ (Table 5) 
Thus indicating that, patients with moderate OA knee not only had a poor quality of life but also had reduced physical function.

\section{Discussion:-}

In our study 22 subjects who visited VPMH were taken, the mean age which was determined for male was 62.5 years and for female was 60.93 years. The reason for including elderly adult was that with increase in age there is increase in morbidity with gradual development of joint pain, stiffness, swelling and limitation of movement which goes with the study done by Ajit NE et al. ${ }^{15}$

Out of the total 22 we got 16 female and 6 male. That means our study shows that the females with moderate OA knee were more in number than males. The probable reason for this rise in females with OA knee could be since Ahmednagar being a rural set up, females here tend to perform farming activities on a daily basis. Their activities include constant standing, frequent squatting and bending activities. Also their postmenopausal status should also be taken into consideration along with their squatting and bending activities, which goes with the findings of the study done by Annil Mahajan et.al. ${ }^{16}$ Our study also showed results similar to Inje Kim et.al study, where have shown that knee OA negatively affects the QOL and physical function in both gender, but women are more adversely affected than men. ${ }^{17}$

According to our results we found out that there is moderately positive correlation of pain (' $r$ ' value- 0.64 , $\mathrm{P}$ value0.0011 ), stiffness (' $r$ ' value- $0.59, \mathrm{P}$ value-0.0033), and physical performance (' $\mathrm{r}$ ' value $-0.67, \mathrm{P}$ value-0.0006) with TUG. Also there is strong positive correlation of WOMAC and TUG (' $r$ ' value- 0.82 , P value- $<0.0001$ ), which indicates as the Quality of life decreases performance time on TUG also decreases. The cardinal symptom of OA knee is pain that affects both quality of life and physical performance, according to Topuz et.al. ${ }^{18}$ Local swelling and pain which are the most common symptoms in OA knee; it is generally due to extravasation of fluid and cells from the bloodstream into the intracellular space. This abnormal accumulation of fluid in the joint cavity is the apparent reason for pain, swelling and restriction of movements, which also goes in accordance with the findings of Ibn Sina et.al. $^{19}$

According to our data, it was revealed that patients with bilateral OA knee $(29.59 \pm 3.98)$ showed more significance than unilateral OA knee $(22.45 \pm 4.11)$ in TUG as well as in bilateral OA knee (79.44 \pm 5.7$)$ was more significant than unilateral OA knee (71.69 \pm 8.19$)$ in WOMAC as well. Thus indicating that there was more patients with disabilities in bilateral moderate OA knee which also coincides with the study done by Mohd Shadab et.al. ${ }^{20}$

Thus moderate OA knee affects day to day activities, which affects quality of life and physical function. Therefore rehabilitation protocol for osteoarthritis of Knee joint should include exercises to improve balance, physical function and thus decrease fear of fall. ${ }^{21}$

\section{Conclusion:-}

The result of this study shows that there is a moderate positive correlation of pain and physical performance, i.e. with increase in pain will significantly affect physical performance. There is also a moderate positive correlation of stiffness with physical performance, i.e. with increase in stiffness there is increase in time of time up and go. Also with poor physical function or difficulty in in performing physical function will cause an increase in difficulty and time of physical performance. Moderate OA knee patients have strong positive correlation between quality of life and physical performance. Thus moderate OA knee affects both quality of life and physical performance. 


\section{References:-}

1. Woolf AD, Pfleger B. Burden of major musculoskeletal conditions. Bull World Health Organ. 2003; 81(9):64656.

2. J Ebnezar. Essentials of orthopaedics for physiotherapist, 1st edition, Jaypee Brothers medical Publishers (P) Ltd., 2003, p.381

3. Felson DT, Lawrence RC, Dieppe PA, et al. Osteoarthritis: new insights. Part 1: the disease and its risk factors. Ann In 7 tern Med. 2000;133(8):635-46

4. Kim HA, Kim S, Seo YI, Choi HJ, Seong SC, Song YW, Hunter DJ, Zhang Y: the epidemiology of total knee replacements in South Korea; national registry data. Rheumatology 2008,47: 88-91

5. Sprangers MA, de Regt EB, Andries F, van Agt HM, Bijl RV, de Boer JB, et al. Which chronic conditions are associated with better or poorer quality of life? J Clin Epidemiol 2000;53:895-907

6. Hunter DJ, Schofield D, Callander E. The individual and socioeconomic impact of osteoarthritis. Nat Rev Rheumatol 2014;10:437-41

7. Luong ML, Cleveland RJ, Nyrop KA, Callahan LF. Social determinants and osteoarthritis outcomes. Aging health 2012;8:413-437

8. Foley SJ, Lord SR, Srikanth V, Cooley H, Jones G. Falls risk is associated with pain and dysfunction but not radiograph $\neg$ ic osteoarthritis in older adults: Tasmanian Older Adult Cohort study. Osteoarthritis Cartilage. 2006; 14(6):533-9.

9. Leveille SG, Jones RN, Kiely DK, et al. Chronic musculo $\neg$ skeletal pain and the occurrence of falls in an older popula $\neg$ tion. JAMA. 2009; 302(20):2214-21.

10. Scott D, Blizzard L, Fell J, Jones G. Prospective study of self-reported pain, radiographic osteoarthritis, sarcopenia pro $\neg$ gression, and falls risk in community-dwelling older adults. Arthritis Care Res (Hoboken). 2012; 64(1):30-7.

11. The prevention of falls in later life: a report of the Kellogg International Work Group on the prevention of falls by the elderly. Dan Med Bull. 1987; 34 Suppl 4:1-24.

12. Leveille SG, Bean J, Bandeen-Roche K, Jones R, Hochberg M, Guralnik JM. Musculoskeletal pain and risk for falls in older disabled women living in the community. J Am Geriatr Soc. 2002; 50(4):671-8.

13. Harrison AL. The influence of pathology, pain, balance and self-efficacy in women with osteoarthritis of the knee. Phys Ther., 2004; 84(9): 822-31

14. Ferrell BA. Pain management in elderly people. J Am Geriatr Soc. 1991;39(1):64-73

15. Ajit NE, Nandish B, Fernandes RJ, Kasthuri A, Shanbhag DN, Goud BR. Prevalence of knee osteoarthritis in rural areas of Bangalore urban district. IJRCI 2014; 1(S1):1-8

16. Annil Mahajan, Vishal Tandon, Sourabh Verma, Sudhaa Sharma. Osteoarthritis and menopause. J Indian Rheumatol Assoc $2005: 13: 21-25$

17. Kim I, Kim HA, Seo YI, Song YW, Hunter DJ, Jeong JY et al. Tibiofemoral osteoarthritis affects quality of life and function in elderly Koreans, with women more adversely affected than men. BMC Musculoskelet Disord. 2010: 22; 11: 129 .

18. Yildiz N, Topuz O, Gungen GO, Deniz S, Alkan H, Ardic F. Health-related quality of life (Nottingham Health Proffile) in knee osteoarthritis: correlation with clinical variables and self-reported disability. Rheumatol Int. 2010;30:1595-1600

19. Ibn Sina Abu Ali. Al Qanoon fit tib. Bairut: Dar Ahyae Turathil Arabi; 2002:54,164,171,187,231,271,301,305,344,360,368,370,749,751,752,823

20. Mohd Shadab, M. Zulkifle, A.H. Ansari, Malik Itrat. Prevalence of knee osteoarthritis in patients visiting NIUM hospital Bangalore. International Journal of Herbal Medicine 2014; 2 (2): 61-64.

21. Jalpa Rasubhai Bhedi et.al., Correlation between fear of fall, balance and physical function in people with osteoarthritis of knee joint, IAIM, 2015; 2(6): 205-209. 